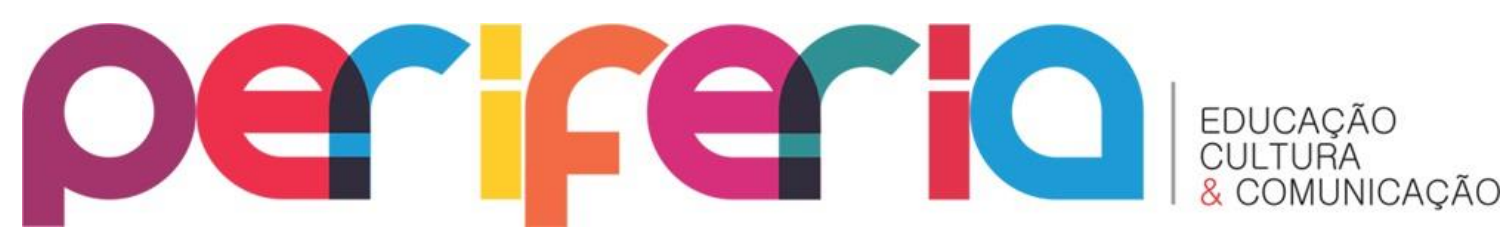

\title{
FORMAÇÃO E SABERES DOCENTES DO PROFESSOR UNIVERSITÁRIO: A REALIDADE NO CURSO DE ADMINISTRAÇÃO DA FCAP/UPE
}

Arandi Maciel Campelo ${ }^{1}$

Faculdade Metropolitana da Grande Recife

\section{RESUMO}

Este artigo trata das fases da formação docente, de professores que lecionam no Curso de Administração, na Faculdade de Ciências da Administração de Pernambuco, unidade de ensino da Universidade de Pernambuco. O estudo objetivou identificar como se deu a formação docente dos professores que exercem suas atividades de ensino na instituição. Para tratar desse tema, utilizamos como referência básica os estudos de Mizukami (2008). Utilizamos a pesquisa qualitativa, com aplicação da entrevista semiestruturada e observação participante, 2009/2010. O estudo revelou que nenhum dos professores teve sua formação acadêmica voltada para o magistério superior, passando a exercer a prática de uma atividade profissional para a qual não tiveram nenhuma formação superior própria; nem intencionalidade para essa formação.

Palavras-chave: ensino superior; formação docente; saberes docentes; construção dos saberes docentes.

\section{FORMATION AND TEACHING KNOWLEDGE OF THE UNIVERSITY TEACHER: THE REALITY INFCAP / UPE ADMINISTRATION COURSE}

\section{ABSTRACT}

This article deals with the stages of teacher education, who teach in the Administration Course at the Faculty of Sciences of Pernambuco Administration, teaching unit of the University of Pernambuco. The study aimed to identify how was the training of teachers exercising their teaching activities in the institution. To study this issue, we

\footnotetext{
${ }^{1}$ Administrador (FCAP/UPE); Doutor em Educação (UFPE); Mestre em Dirección y Organización de Hospitales y Servicios de Salud (Universidad Politécnica de Valencia); Mestre em Planificación y Gestión Organizacional (Universidad Autónoma de Madrid); Professor universitário, desde 1986; Consultor Organizacional, desde 1984; livros publicados: "Gestão de Pessoas", "Administração de Atividades no Tempo", "Saberes Docentes".
} 


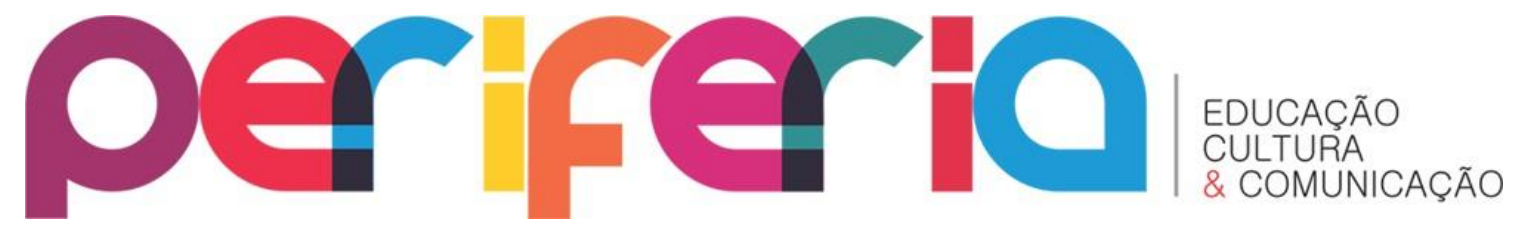

used as a basic reference the studies of Mizukami (2008). We use qualitative research with application of semi-structured interviews and participant observation 2009/2010. The study found that none of the teachers had focused his academic training for the higher education, going to engage in the practice of an occupation for which they had no own higher education; or even intent for this training.

Keywords: higher education; teacher training; teaching knowledge; construction of the teaching knowledge 


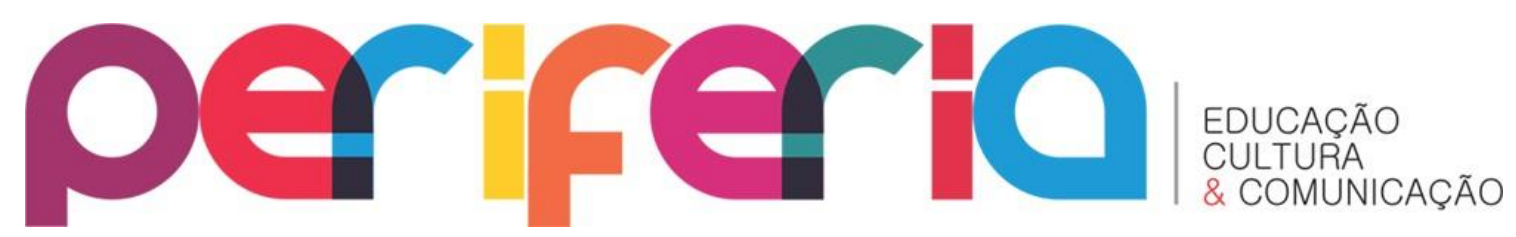

\section{INTRODUÇÃO}

Este artigo é resultado de pesquisas realizadas sobre a formação docente de professores que atuam no curso superior de Administração da Faculdade de Ciências da Administração de Pernambuco, unidade de ensino integrante da Universidade de Pernambuco - FCAP/UPE, no período de 2009 e 2010. Nele procuramos demonstrar as influências que o futuro professor sofre, na sua formação, desde o contexto familiar, perpassando pelo ambiente escolar até seu ingresso no mercado como profissional do ensino. Mizukami (2008) segmenta esse percurso em três grandes etapas: uma etapa iniciada no ambiente familiar, antes mesmo do ingresso nos bancos escolares da formação básica; outra etapa que tem início quando se ingressa intencionalmente na universidade, buscando essa formação superior (de profissional professor); e a terceira etapa, que tem início nos primeiros contatos práticos da profissão, em sala de aula, como estagiário, e, posteriormente, como professor iniciante.

O artigo está estruturado em dois momentos: (i) em que apresentamos a base do referencial teórico que norteou a realização da pesquisa; (ii) em que analisamos os dados extraídos de campo, à luz do referencial teórico levantado, com o propósito de identificar as principais etapas percorridas pelos professores investigados, durante seu processo de formação docente, para o ensino superior.

\section{FORMAÇÃO DOCENTE: O REFERENCIAL TEÓRICO}

A formação de um professor não é algo pontual, ou que possa ser realizado em curto tempo, pois implica uma história de vida desse profissional, que tem um ponto de partida, situado no ambiente familiar, sem um ponto de chegada. Trata-se de um processo que vai acompanhá-lo durante toda a sua trajetória de vida, pessoal e profissional. Nesse espaço de tempo muitos aspectos dos vários ambientes de vivência e convivência vão incorporando-se à sua personalidade, a seu modo de ser, ver, de lidar com esses ambientes e também de influenciá-los. Na verdade, sua formação consiste numa conjugação de inúmeras e distintas fases ao longo de sua vida que, por isso mesmo, podemos compreendê-la na mesma perspectiva abordada por Mizukami 


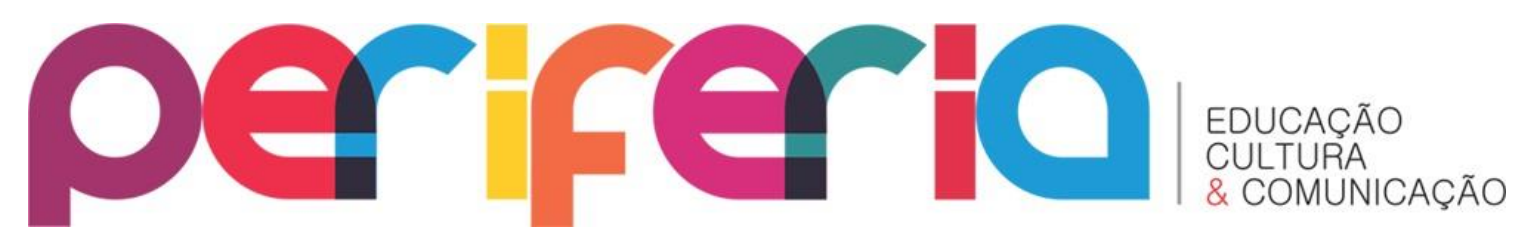

(2008, p. 389): “[...] os processos de aprender a ensinar e de aprender a ser professor são lentos, pois se iniciam antes do espaço formativo dos cursos de licenciatura e se prolongam por toda a vida profissional."

Nessa mesma compreensão, Ferenc e Saraiva (2010) dizem que, ao se falar sobre a formação docente, dever-se-ia, na verdade, falar do seu processo de socialização profissional, porque tal formação envolve uma série de distintas e complexas vivências em ambientes distintos, com pessoas distintas, em contextos igualmente distintos.

É um processo longo, lento e crescente, em que se vão formulando e solidificando uma série de crenças, valores, habilidades e aptidões difíceis de serem modificadas quando esse profissional encontra-se em pleno exercício de suas atividades educativas, já na fase adulta. Se tais características forem construídas em boas bases referenciais, sejam as do contexto familiar, as do ambiente escolar, sejam mesmo nos diversos ambientes sociais de modo geral, certamente esse profissional poderá ser muito mais que um simples professor: um educador, como sugere Gil (2006, p. 23): “Os educadores são como uma árvore frondosa, são formados com o tempo. São mais raros que os professores, porque agregam tudo o que se espera de um mestre: a paciência, a sabedoria, a crítica, a solidez de valores."

Como educador, o professor passa a assumir grandes desafios, não apenas perante a sociedade, mas também para consigo mesmo. Desafios que ele próprio precisa e deve incorporar como compromissos pessoais, profissionais e, sobretudo, sociais. Para tanto, o professor necessita estar ciente e consciente dessa sua necessidade e responsabilidade, não apenas profissional, mas também pessoal, que podem ser muito bem supridas com uma adequada formação pedagógica, como parece ser o caso da crença apresentada pelos professores investigados por Ferenc e Saraiva (2010, p. 586): “[...] os professores investigados, sem exceção, ao sinalizarem suas necessidades, bem como as possibilidades formativas para a melhoria de sua prática docente, reconhecem uma demanda pessoal, principalmente no que se refere à formação pedagógica." 


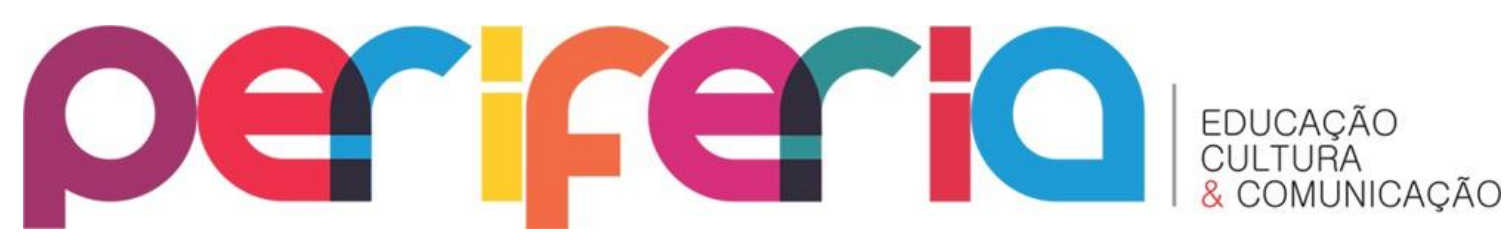

Essas necessidades podem ser observadas em dois distintos e complementares movimentos. No primeiro, em que esse profissional precisa aprender a ser, muito mais que ter. No segundo movimento, em que ele precisa entender que vai lidar não apenas com a instrução escolar, mas também com a formação e educação do seu semelhante - o ser humano, seu aluno. Desafios respaldados nas palavras de Ducros (1986, p. 179): “[...] propiciar una formación que, sin ignorar la importancia de los conocimientos que permiten enseñar esta o aquella disciplina, de la supremacia al ser sobre el tener (y el saber es una forma de tener), ése es el objetivo de una verdadera formación de los maestros [...]".2

Quanto ao segundo movimento, o professor, como educador, deve entender que terá como tarefa lidar com a formação de um ser imbuído de pensamentos, desejos, necessidades, crenças, valores, ambições, cujas influências decorrem do próprio "eu", do convívio com os outros, e do mundo de modo geral, porque assim como o professor, cada ser (o aluno) também tem a própria trajetória de vida, regada de influências anteriores, até chegar ao mundo escolar, seja no âmbito da formação básica, fundamental, média, seja superior. É por intermédio desse ser, com toda a sua complexidade, que o professor, como sujeito, terá a desafiante missão de contribuir para a transformação de si mesmo, desse ser (seu educando) e da realidade em que vive, em decorrência do seu trabalho e de sua intencionalidade (PLACCO, 2006).

A diversidade e a complexidade de situações (e experiências) que o professor acumula ao longo da sua história de vida moldam sua formação a uma série de fatores que não podem ser facilmente mensurados, pois envolvem variáveis relativas às noções que nele vão sendo formuladas sobre os conceitos de hierarquia, de poder, regras, disciplina, controle, crenças e valores, cujas origens estão enraizadas no seio familiar quando esse profissional era apenas uma criança. É um processo que, embora seja bastante complexo, vai proporcionando sentido à estruturação da identidade desse futuro profissional da educação.

\footnotetext{
2 “[...] proporcionar uma formação que, sem ignorar a importância dos conhecimentos que permitem ensinar esta ou aquela disciplina, da supremacia do ser sobre o ter (e o saber é uma forma de ter), esse é o objetivo de uma verdadeira formação de professores [...]". (Tradução livre).
} 


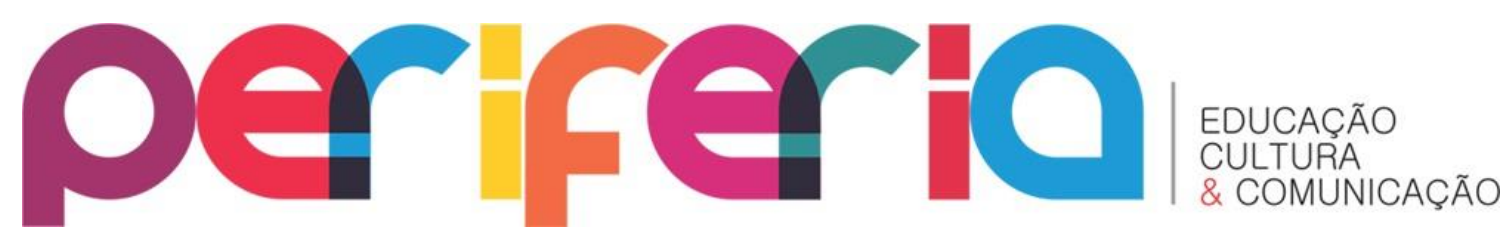

Abraham et al. já apresentavam esse entendimento, dando maior ênfase aos aspectos relativos à afetividade humana, juízo de valor e valores que o futuro professor vai incorporando à sua identidade, quando afirma: "[...] en el docente hay toda una trama de identificaciones que se refiren a vivencias afectivas, a juicios, a valores [...]." (ABRAHAM et al., 1986, p. 21). ${ }^{3}$

Para Mizukami (2008), o processo de formação e desenvolvimento docente, no caso daqueles que buscam a formação específica para esse ofício, por meio dos cursos regulares, pode ser melhor compreendido se analisado a partir das seguintes etapas:

a) uma etapa iniciada fora da universidade, onde os conhecimentos (saberes diversos) que contribuirão para sua formação são incorporados de maneira não sistematizada e, até mesmo, não intencional, por contemplar tudo o que aconteceu ao longo da vida desse futuro professor - essa etapa tem seu início no seio familiar, em que o profissional receberá as primeiras influências para o exercício da profissão, havendo ou não essa intenção do grupo social familiar;

b) uma segunda etapa, em que há a intencionalidade da escolha da profissão, seja por "imposição do mercado", seja por influência familiar e escolar. Essa etapa tem seu início no momento em que a pessoa faz sua escolha, direcionando a formação profissional para a área da Educação e ingressa na universidade. Durante sua trajetória acadêmica, o futuro professor passa a incorporar conhecimentos (saberes docentes) de natureza teórica, que são sistematizados e "pedagogicamente" transmitidos pela universidade;

c) uma terceira etapa, que tem início nos primeiros contatos práticos com a profissão, em uma sala de aula, na condição de estagiário e, posteriormente, de professor iniciante, legalmente habilitado para a atividade docente, que se estenderá por toda a sua carreira de professor.

A autora enfatiza que "o processo de aprendizagem e de desenvolvimento profissional da docência é entendido como um processo espiralado de modificação

\footnotetext{
3 “[...] No professor, há toda uma trama de identificações que se referem a vivências afetivas, a juízos, a valores [...]." (Tradução livre).
} 


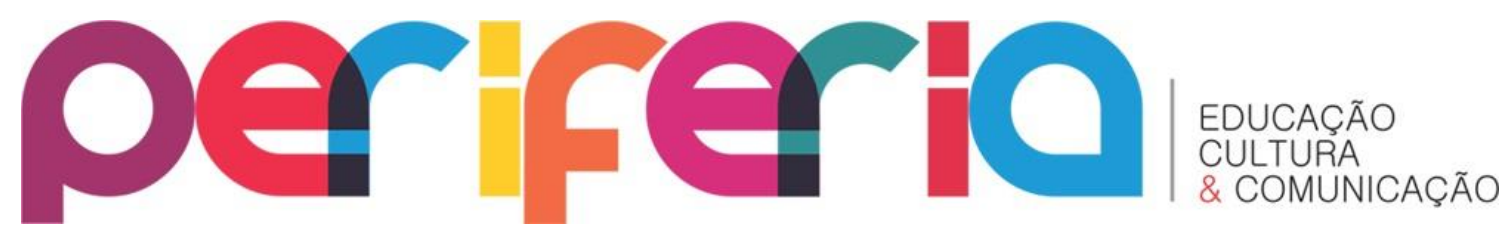

contínua e de práticas pedagógicas em função da ampliação da base de conhecimentos" (MIZUKAMI, 2008, p. 395). Esse espiral tem um ponto de partida que, embora esteja situado no ambiente familiar, é bastante difícil ser identificado com precisão, uma vez que está localizado em determinado ponto da vida pessoal e social do professor, muito distante do momento em que decidiu iniciar a própria profissão docente. Não tem um ponto de chegada por se estender ao longo de toda a vida desse profissional. A chegada à instituição de ensino superior, portanto, não pode ser caracterizada como a fase inicial; tampouco sua saída como a fase terminal da formação desse profissional. Ela é a continuidade daquilo que foi iniciado no ambiente familiar.

Esse entendimento de Mizukami encontra-se em Charlot (2001, p. 149), que afirma: "Os jovens aprendem muitas coisas antes de entrar na escola e continuam a aprender [...] Não se vai à escola para aprender, mas para continuar a aprender."

Desse modo, a formação docente é um processo muito rico, dinâmico e complexo, uma vez que, durante esse trajeto espiralar, muitas mudanças na vida desse profissional certamente ocorreram e continuarão a ocorrer durante toda a sua carreira em decorrência de inúmeras variáveis presentes no contexto de sua formação pessoal, familiar, social, escolar, política, cultural, econômica, financeira.

Nesse processo de construção de saberes em espiral, o professor passa a desenvolver sua capacidade de atuar, não apenas como um mero transmissor de conhecimentos, mas como um verdadeiro educador conforme a abordagem demonstrada por Gil (2006) e mais adiante entendida por Donato (2008, p. 435), que considerou o professor como um "facilitador del proceso de enseñanza y aprendizaje". Dessa forma, trata-se de um processo de amadurecimento profissional em que o professor deixa de ser professor e passa a ser educador. Como tal, incorpora a capacidade e responsabilidade de lidar com situações complexas, de proporcionar momentos reflexivos entre seus alunos, seus pares e, assim, passará também a contribuir, efetivamente, para a construção de conhecimentos capazes de influir na transformação dos homens (seus alunos) e da sociedade. 


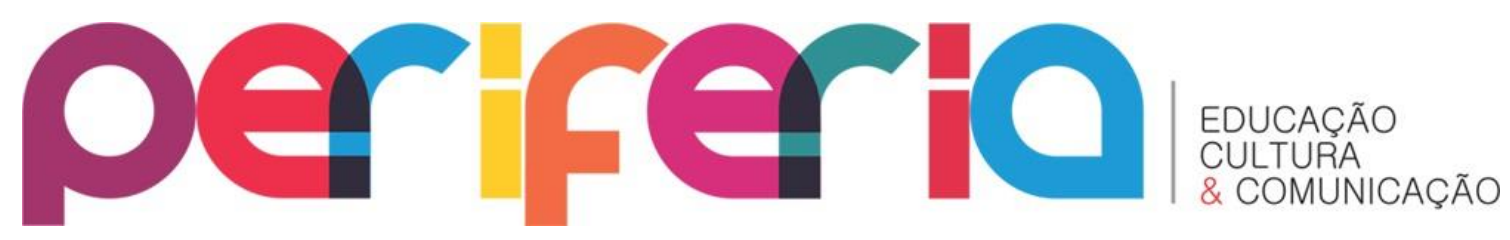

O entendimento de Gil (2006), Mizukami (2008) e Donato (2008) sobre a complexidade dessa formação segue a mesma percepção de Tardif (2005), que já considerava a formação docente e, por consequência, a própria construção do seu saber como um processo de múltiplas, diversas e complexas fases, que acompanham esse profissional ao longo de toda a sua história de vida, uma vez que decorre de várias experiências, que incluem desde a estrutura familiar até as experiências da profissão no ambiente escolar.

\section{FORMAÇÃO DOCENTE: O QUE A REALIDADE DE CAMPO NOS MOSTROU}

Embora as origens, os momentos e a motivação que levaram os professores investigados a ingressar nas atividades de ensino superior de administração tenham sido distintos, constatamos que houve um alto nível de evidências correspondentes, no que se refere ao reconhecimento e valorização de que tiveram sua "preparação formal" para a docência superior, quando já estavam atuando na universidade - seja quando eram apenas alunos, seja já na condição de professor universitário.

Para Mizukami (2008), esse momento corresponde à terceira etapa da formação docente, quando o futuro professor, ainda na condição de aluno, inicia os primeiros contatos práticos como estagiário de ensino e, posteriormente, como professor iniciante, legalmente habilitado para esse ofício. Essa autora, ao apresentar as etapas da formação docente, reporta-se aos que seguiram essa carreira profissional intencionalmente, focando a formação universitária nessa direção. Não é o caso dos professores investigados neste estudo, pois nenhum deles teve sua formação voltada para o magistério no nível superior. Embora a instituição (FCAP/UPE) não se tenha preparado para torná-los professores na perspectiva formal, recebendo-os como se já o fossem (PIMENTA, 2005), os professores reconhecem que foi na instituição de ensino superior que receberam "sua preparação formal" - prática - para o exercício da docência superior de administração.

Nesse contexto, cabe destacar que, para Mizukami (2008), o processo de aprender a ser professor é lento, tem início muito antes dos espaços formativos das 


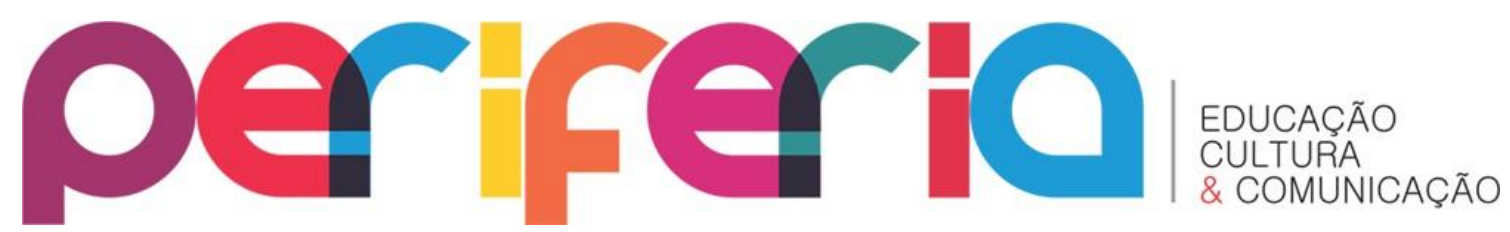

licenciaturas e se prolonga por toda a vida desse profissional. A autora compreende essa formação em três distintas etapas: a primeira, iniciada fora da instituição de ensino superior; a segunda etapa segue no momento em que o futuro professor ingressa intencionalmente num curso de formação específica para o magistério; e a terceira etapa, quando esse futuro profissional, já na condição de aluno universitário, inicia os primeiros contatos práticos como estagiário de educação e, posteriormente, como professor iniciante, legalmente habilitado para as atividades do ensino escolar.

Todos os professores investigados neste estudo passaram pela primeira etapa, iniciada fora da instituição de ensino superior, em que são incorporados conhecimentos (saberes diversos) de maneira não sistematizada e, até mesmo, não intencional, vivenciados em vários ambientes sociais, inclusive o familiar. Afinal, nela o futuro professor adquire conhecimentos oriundos das relações familiares, necessários ao exercício da docência, mesmo que não tenha essa intenção, conforme ressalta Mizukami (2008). Portanto, uma etapa que tem origem na infância, no seio familiar e se estende até o momento que antecede o ingresso na universidade.

Nessa etapa, seja como criança, adolescente, estudante, seja profissional consultor, nos dados da pesquisa, o nível de evidências correspondentes se mostrou alto, uma vez que todos os professores investigados se referiram a essa etapa como a de expressiva influência na sua formação docente. Alguns relembraram momentos da própria infância/adolescência, com certo saudosismo, conforme podemos observar nos seguintes depoimentos:

Isso é vocação, eu dou aula desde menino. (Professor I).

[...] quando fazia o fundamental, ocorreu de um colega ficar precisando tirar 9,5 para passar no colégio do interior. Eu tinha na época uns 15 a 16 anos e me pediram que eu fosse ajudar essa pessoa. Foi a minha primeira experiência de ensino. (Professor IV).

Para Cunha (2010), atribuir à docência a concepção de ser um dom, ou vocação, como verbalizado pelo Professor I, pode caracterizar certo desprestígio e desvalorização do conhecimento pedagógico na formação de todos os níveis de 


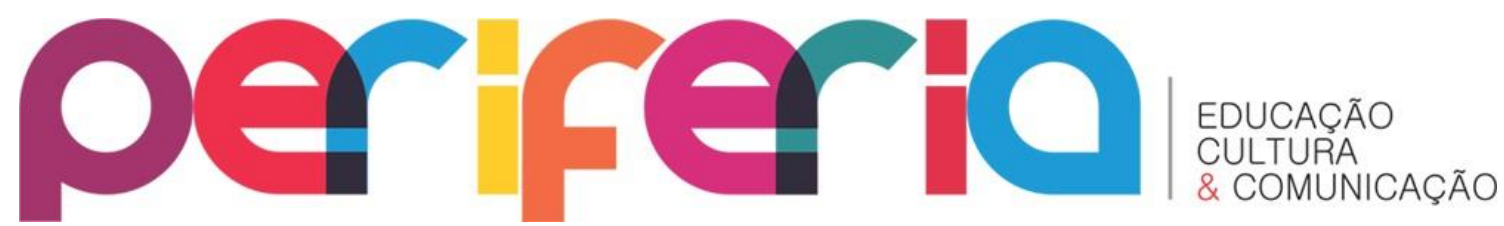

ensino, sobretudo para o ensino superior. Contudo, essa não parece ter sido a intenção do professor, porque em campo ele demonstrou valorizar não apenas a profissão professor, mas também sua formação respaldada em bases científicas, como é possível observar no seguinte registro:

O professor começou uma de suas aulas indagando a cada aluno: 'você quer ser professor?' Nenhum aluno respondeu positivamente. Em seguida, afirmou: 'Vejam, ninguém aqui quer ser professor, mas se não for o professor, o mundo para. Como é possível produzir e transmitir conhecimento se não for por intermédio do professor? [...] O professor é um diretor e está aqui fazendo o quê? Pesquisando, gente! Se isso não fosse importante, ele não estaria aqui [...]; precisamos formar professores para a universidade e sem as pesquisas dos professores universitários, isso não seria possível. (Professor I).

Ao falar de sua atividade docente, o professor demonstrou profundo sentimento de prazer pelo ofício que exerce desde a infância. Narrou essa passagem com emoção, com vibração, numa nítida demonstração valorativa do trabalho docente que abraçou. Dizia também que não tinha certeza se os métodos por ele adotados eram os mais corretos e se tivesse uma orientação pedagógica nesse sentido, talvez a realizasse com maior segurança.

Já na segunda etapa, caracterizada pelo ingresso intencional num curso de formação específica para o trabalho docente, o nível de evidências correspondentes se mostrou inexistente, pois nenhum dos seis professores teve sua formação acadêmica na área da educação. Dos 69 professores que fazem parte da instituição investigada, apenas 1 tem formação em educação - uma professora que leciona como docente convidada. Um cenário típico de uma área que, ao não ser reconhecida como campo específico da Pedagogia, em seu nível superior, como também no próprio nível médio, "[...] se tornou alienígena em definição da própria área e essa condição repercute na legitimação dos conhecimentos necessários a suas práticas", segundo Cunha (2010, p. 74).

Apesar de nenhum dos professores investigados ter buscado uma formação específica para o magistério superior, foi na terceira etapa que encontramos certa 


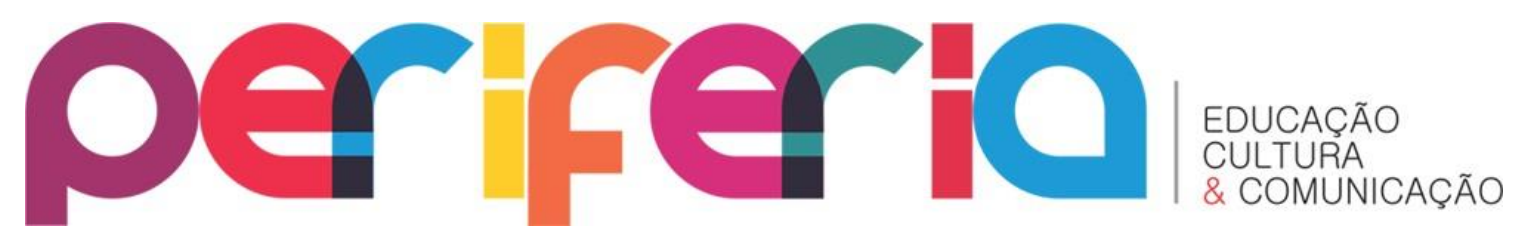

compatibilidade com o que nos apresentou Mizukami (2008), ou seja: a etapa em que o futuro professor ou o já professor inicia suas atividades docentes na instituição de ensino superior. Nessa etapa, cinco dos seis professores demonstraram haver recebido pelo menos parte do que seria sua "preparação formal" para a formação docente por meio de cursos de didática e metodologia do ensino superior, o que atribui a essa questão um alto nível de evidências correspondentes, como foi possível verificar no depoimento desses professores.

Apenas o Professor I não verbalizou sua passagem por essa etapa na construção de sua formação docente. Mesmo assim, é inegável que não a tenha vivenciado no momento em que iniciou o ofício da docência no Curso Superior de Administração, cursando posteriormente seu mestrado em Administração. Por outro lado, devemos entender que a formação docente, na realidade, não se inicia no momento em que o futuro professor ingressa na universidade, num curso de formação específica. Para Rocha (2008) e Vidal (2010), tal formação é um processo que tem início no momento em que a pessoa ingressa nos bancos escolares, na condição de estudante; desde sua formação básica, de onde assimila e passa a seguir parte da rotina, do modo de ser e de agir de antigos professores, complementam Benedito e Ferrer (1995).

Analisando essas etapas em conjunto, encontramos outro nível alto de evidências correspondentes, pois todos os seis professores seguiram o mesmo percurso de etapas na sua "formação", ou seja, partiram da etapa (primeira) que antecede o ingresso na instituição de ensino superior na condição de alunos diretamente para os primeiros contatos práticos com a profissão: a terceira etapa. Passando a exercer a prática de uma atividade profissional para a qual não tiveram nenhuma formação superior própria.

O que difere os estudos apresentados por Mizukami (2008) da realidade demonstrada pelos professores investigados é o fato de terem ingressado no exercício da atividade docente sem nenhuma preparação formal ou legal, ou mesmo intencionalidade de buscar um curso superior que lhes atribuísse a habilitação para ser 


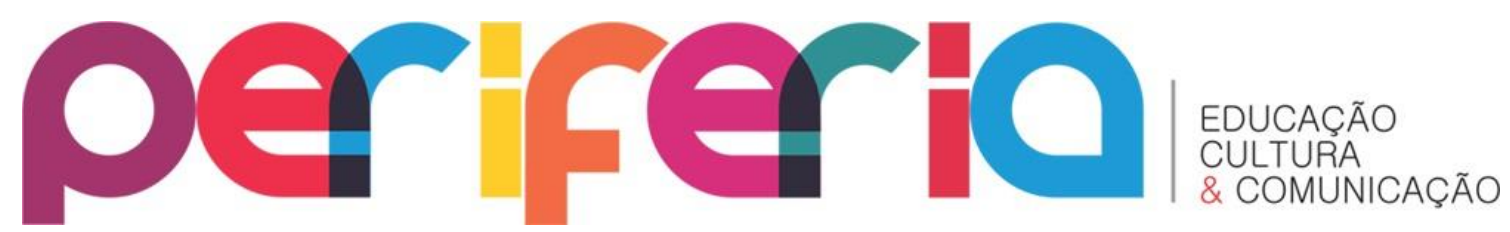

professor. Desse modo, deixaram de realizar o que seria uma das mais importantes etapas de sua formação docente: a segunda, em que surgiria a escolha intencional da profissão, com seu ingresso num curso superior de formação específica para o exercício profissional nesse nível de ensino.

Segundo Ferenc e Saraiva (2010), essa é uma necessidade reconhecida por 32 professores universitários do Centro de Ciências Humanas, Letras e Artes, iniciantes no magistério, da Universidade Federal de Viçosa, Minas Gerais. Para esses profissionais, numa demonstração de necessidade pessoal, a medida mais primordial para a melhoria das práticas docentes reside numa boa formação pedagógica, também na instituição de que fazem parte como professores universitários.

À parte as questões da intencionalidade ou legalidade dessa formação, o fato é que cinco dos seis professores investigados afirmaram que os cursos de didática ou de metodologia do ensino superior que realizaram para essa finalidade constituíram "sua formação docente" para o ensino superior, que hoje exercem no curso de administração.

Ora, uma "formação", assim pontual, não é suficiente para o bom exercício da atividade docente. Contudo, não podemos desconsiderar que os cursos de didática ou de metodologia do ensino superior pelos quais passaram contribuíram para essa formação. Afinal, trata-se de uma prática comum nas instituições de ensino superior, que oferecem esses cursos com a finalidade de suplantar a ausência de formação pedagógica de seus professores (GIL, 2006).

Corroborando com Gil (2006), Cunha reforça o entendimento da precariedade na formação docente, destacando: “[...] a carreira universitária se estabeleceu numa perspectiva de que a formação do professor requer esforços, apenas, na dimensão científica do docente, materializada pela pós-graduação stricto sensu [...]" (CUNHA, 2010 , p. 29), conforme estabelecido na própria LDB de 1996, em seu artigo 66, definindo que a preparação para o exercício do magistério superior se fará em nível de pós-graduação, prioritariamente em programas de mestrado e doutorado. 


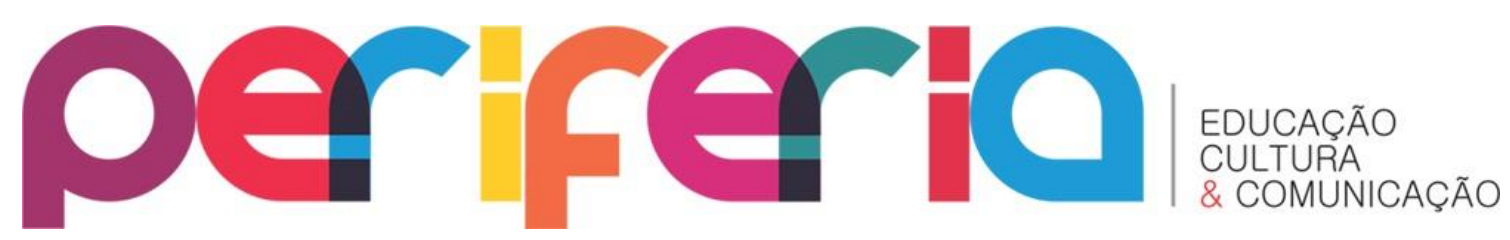

A forma como se deu a preparação dos professores investigados neste estudo para o trabalho docente não seguiu sequer o insuficiente "modelo" citado e criticado por Cunha (2010), pois a pós-graduação stricto sensu para cinco deles somente se realizou quando já exerciam suas atividades no magistério superior. Sua formação ficou, portanto, restrita aos eventuais cursos de didática e metodologia do ensino superior, também criticado por Gil (2006). Mesmo assim, consideramos oportuno apresentar as distintas maneiras dessa formação no que se relaciona com o contexto e a finalidade em que se realizou.

Para o Professor II, foi um curso de oratória e de didática que recebeu para atuar como consultor, quando já era formado em engenharia, antes de ingressar nas atividades do magistério superior. Contudo, a preparação recebida foi proporcionada por uma instituição não universitária (o Sebrae), cuja finalidade era a de prepará-lo para ser instrutor em atividades de consultoria, e não para atuar como professor do ensino superior. Nos demais casos, foram os cursos de didática e metodologia do ensino superior realizados esporadicamente, desde que eram alunos, que seguiram no mesmo caráter não sistemático quando já lecionavam na FCAP/UPE.

Das diversas falas das entrevistas, uma chamou bastante atenção, por contemplar, de certa forma, as falas dos demais professores da pesquisa:

Fiz alguns cursos esporádicos quando já era professor universitário, especificamente para ser uma pessoa que entendesse de didática, de metodologia do ensino, de desempenho em sala, mas eu nunca tive isso sistematicamente. Por ter estudado psicologia, havia uma ênfase muito forte nas questões da pedagogia, que foram marcantes. Tive muito contato com o pessoal de didática e educação e fui formando essa experiência na prática, em sala de aula. Às vezes, imitava um pouco os professores que tinham uma boa forma de condução dos alunos. (Professor III).

Para esse professor, como ocorreu com a maioria dos outros investigados, sua preparação para o magistério foi na própria universidade, embora tenha sido num curso cujo propósito não seria a formação docente; no caso desse professor, quando ainda era aluno do curso superior de Psicologia, de onde afirmou ter percebido a grande ênfase que o curso dava às questões da pedagogia. 


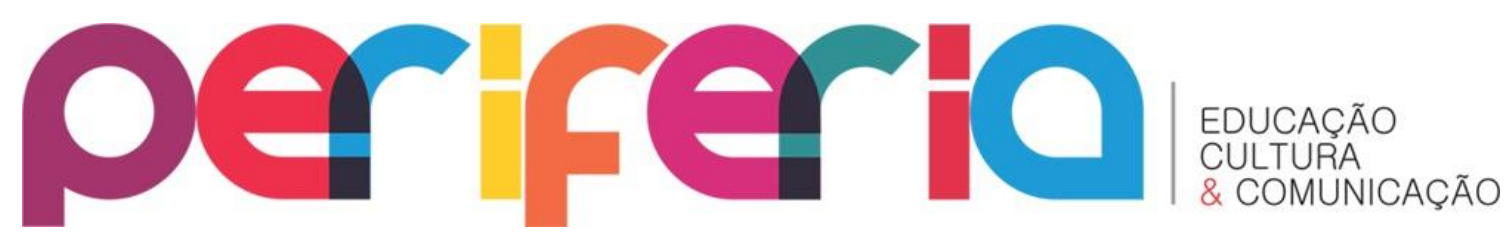

$\mathrm{Na}$ sua fala, identificamos grande valorização não apenas da questão da didática, mas principalmente da própria pedagogia quando afirmou que em seu curso de psicologia houve forte ênfase "nas questões da pedagogia, que foram marcantes". Esse sentimento de valorizar o pedagógico é algo muito atual, porque os professores universitários, com ou sem essa formação, reconhecem nela existir as melhores possibilidades formativas para a prática docente. Percebemos essa realidade quando observamos a crescente participação dos professores deste campo investigativo nos encontros pedagógicos semestrais promovidos pela FCAP/UPE. Nada obstante, de forma visivelmente contraditória, o saber da ação pedagógica, embora seja o mais requisitado pelos professores, quando falam da necessidade de aprimorarem a profissionalização no ensino superior, como registrado nas pesquisas de Ferenc e Saraiva (2010), é o menos desenvolvido nos processos de formação docente, conforme ratificam Ramos e Simonini (2010).

Nesse contexto, é visível que a questão da formação pedagógica vai mais além que a própria necessidade institucional demonstrada por Gil (2006), porque aqui percebemos tratar-se de uma demanda de natureza também pessoal, como verbalizou o Professor III.

Outro aspecto relevante na fala desse professor foi quando expressou: "Às vezes, imitava um pouco os professores que tinham uma boa forma de condução dos alunos." Essa afirmativa, associada ao momento anterior, quando revelou que a ênfase nas questões pedagógicas, proporcionada pelo seu curso de psicologia, havia sido algo marcante na sua formação docente, encontra ressonância nas pesquisas de Goodson (2007). Esse pesquisador constatou a influência que antigos professores acabam exercendo sobre a formação dos alunos, futuros professores, mesmo fora do contexto dos cursos de licenciatura, ou seja: "Uma característica comum do ambiente sociocultural colhida nas narrativas dos professores é o aparecimento de um professor preferido que influenciou, de um modo significativo, a pessoa enquanto jovem aluno." (GOODSON, 2007, p. 72). Como o Professor III se referiu sempre no coletivo - "ênfase muito forte nas questões da pedagogia; contato com o pessoal de didática"; imitando 


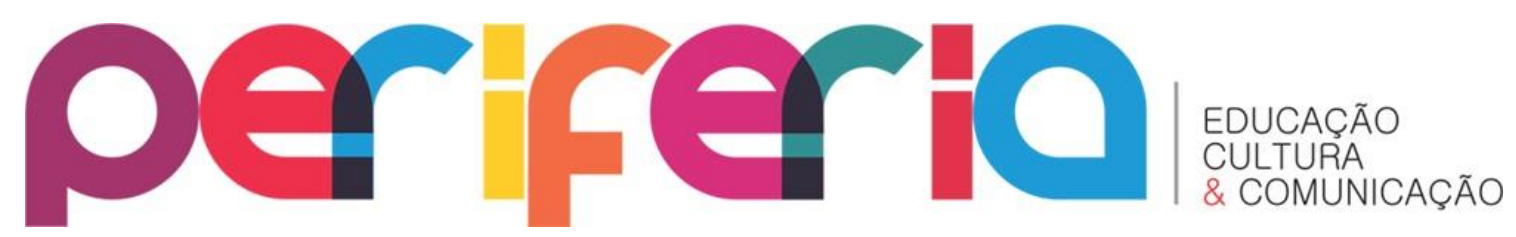

os bons professores - certamente não foi apenas um professor que serviu de referência para balizar seu modo de agir no exercício da atividade docente, como considerado pelo autor - "um professor preferido" -, porque, como ele mesmo afirmou, "às vezes, imitava um pouco os professores que", na sua concepção, demonstravam maior desenvoltura na condução do seu ofício.

Ao admitir ter-se inspirado em seus bons professores, na forma de condução dos alunos, o professor reconheceu haver recebido as primeiras influências de sua formação docente quando ainda era estudante universitário. Fato esse compatível com as pesquisas realizadas por Cunha, que afirma: "[...] os atuais professores são bastante influenciados no seu comportamento pelos antigos e, certamente, poderão influenciar os que virão." (CUNHA, 2006, p. 91. Mais adiante, a autora reforça em novas pesquisas: "[...] os docentes reconhecem nos seus ex-professores a inspiração mais forte de sua configuração profissional. E essa configuração se aguça, quando se trata de professores universitários [...]." (CUNHA, 2008, p. 469).

Levando em consideração que todos os professores investigados têm mais de onze anos de ensino na FCAP/UPE, e os cursos de didática ou metodologia para o ensino superior ocorreram predominantemente quando já eram graduados ou logo no início de suas atividades na própria instituição, é impossível acreditar que esses cursos de alguma maneira não tenham contribuído para a "formação" desses profissionais, por contemplarem em seu conteúdo elementos próprios da pedagogia, mesmo que essa preparação tenha sido algo pontual e, portanto, insuficiente.

O tempo médio de ensino desses profissionais na FCAP/UPE é de dezoito anos e, assim, podemos considerar todos como professores veteranos da instituição. Nessa fase da carreira docente, é natural que muitos professores se tornem mais flexíveis, tolerantes, portanto, mais abertos aos ensinamentos da pedagogia, também demonstrando sua maturidade profissional, realça Fontes (2009). Logo, é natural o valor que a expressiva maioria deles atribuiu aos cursos de didática e de metodologia vivenciados no passado, conseguindo incorporar e expressar com mais facilidade e 


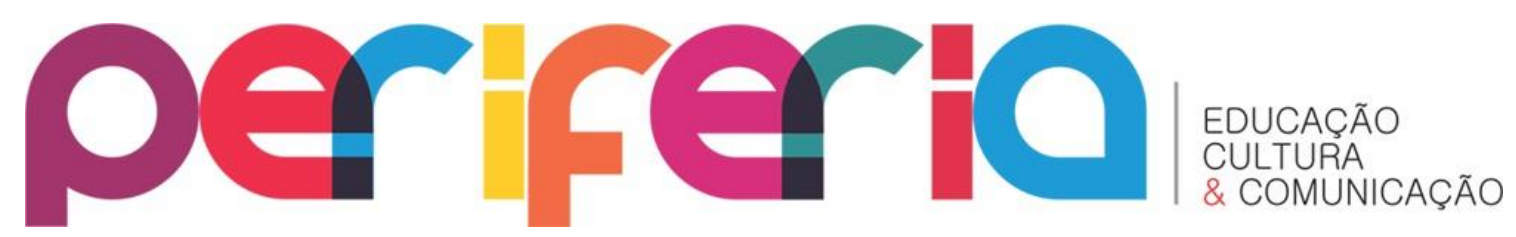

liberdade pelo menos um pouco dos elementos da pedagogia que receberam nessa "preparação".

Outro alto nível de evidências correspondentes foi o ato de aprender pela prática, ou seja: o aprender a fazer "fazendo". Um aspecto também destacado pelo Professor III ao se referir à construção de sua prática de ensino na própria sala de aula. Em seus depoimentos, todos os seis professores de certa forma falaram dessa "preparação" por meio de uma prática exercida no contexto de diversas atividades próprias do ensino.

Quatro deles revelaram que essa formação, decorrente da prática de ensino, ocorreu antes mesmo de ingressarem na universidade, ou seja: ministrando aulas no Movimento Brasileiro de Alfabetização (Mobral); quando era aluno do fundamental, ajudando os colegas menos preparados, e realizando treinamento e capacitação de seus clientes de consultoria.

Não conseguimos identificar nessas falas se houve ou não uma ação transformadora em suas práticas, porque participar da alfabetização funcional de jovens e adultos - o caso do Mobral -, ajudar os colegas menos preparados do ensino fundamental e treinamentos e capacitações de consultoria, por si só, não é suficiente para que se possa revelar como práxis social. Práticas que, se exercidas com intencionalidade, podem dar sentido à formação docente de maneira direcionada e contextualizada, contribuindo, assim, para a transformação da realidade social em que vivemos (CHARLOT, 2005).

Tomando como referência a realidade coletada nas observações em campo, percebemos baixo nível de evidências correspondentes entre as falas das entrevistas e o que foi verbalizado nas práticas de sala de aula. Os professores, de modo geral, não fizeram quaisquer tipos de referência à importância de sua formação (preparação) para o ensino superior, exceto dois deles, o P I e o P IV. Esses professores destacaram a trajetória profissional desde a infância, nos moldes da primeira etapa do processo de formação docente considerado por Mizukami (2008), em que está presente tudo o que 


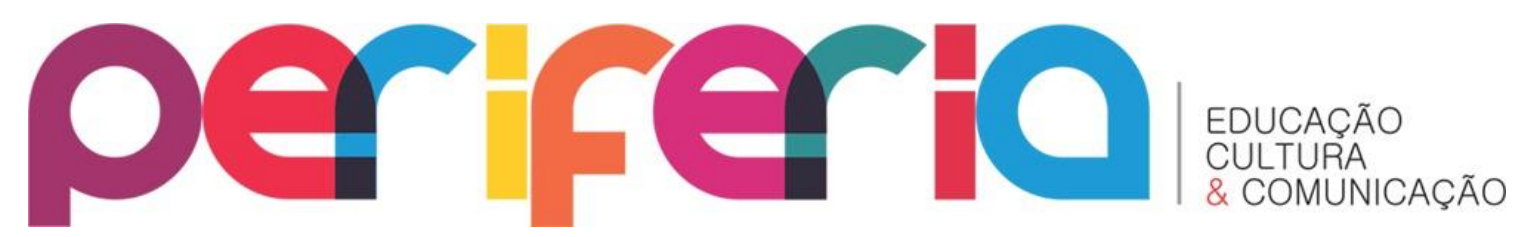

é vivenciado pelo professor, antes do seu ingresso no ensino superior, na condição de aluno - a segunda etapa dessa formação.

$\mathrm{Na}$ análise das etapas que compreendem a formação docente, cabe, ainda, ressaltar que o pensamento de Mizukami (2008) pode ser complementado por Tardif (2005), por considerar, além das três etapas descritas pela autora, as experiências na profissão, que podem ocorrer dentro e fora da instituição de ensino superior. Nesse sentido, todos os professores trouxeram para suas práticas experiências (de consultoria), vivenciadas fora da universidade que, de certo modo, contribuíram para sua formação docente. Mesmo assim, devemos admitir: em nenhum momento, esses professores se referiram às experiências não docentes como momentos de contribuição para essa formação (docente), exceto em suas falas durante as entrevistas. Quando traziam para a sala de aula as experiências profissionais, era tão somente como forma de relacionar a teoria construída pela universidade com as práticas vivenciadas no (e pelo) mercado.

\section{CONSIDERAÇÕES FINAIS}

O estudo teve como objetivo identificar com se deu a formação docente de professores que exercem suas atividades de ensino na FCAP/UPE.

Tratando da formação para o exercício da docência, constatamos que nenhum dos professores investigados teve sua formação acadêmica voltada para o magistério, no nível superior. A instituição (FCAP/UPE), por sua vez, os recebera como se a tivessem, limitando-se a oferecer apenas cursos de didática e metodologia do ensino superior, de forma pontual e não sistemática. Mesmo assim, esses professores, em seus depoimentos, valorizaram bastante essa "sua preparação formal", proporcionada pela instituição, embora saibamos que uma "preparação", assim, pontual não seja suficiente para a boa formação docente, sobretudo para atuar no ensino superior.

Desse modo, podemos afirmar: esses professores passaram a exercer a prática de uma atividade profissional para a qual não tiveram nenhuma formação superior própria; sem a intencionalidade de buscar um curso que lhes proporcionasse a 


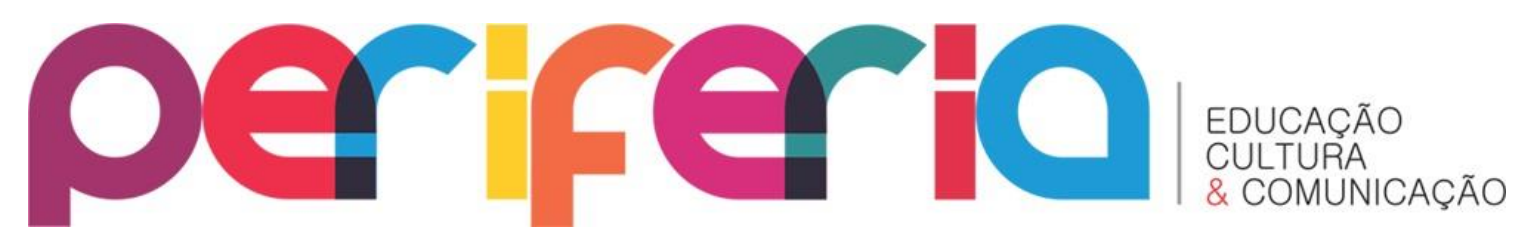

habilitação técnica e legal, para ser professor universitário, deixando uma lacuna na sua formação profissional, que deveria ter sido preenchida com a realização de um curso superior de formação específica para o exercício do magistério superior.

Independentemente de onde foi mais marcante a influência na formação docente, para esse nível de ensino, se no âmbito familiar, escolar, universitário, se em qualquer outro ambiente, o professor deveria ser mais ouvido e valorizado sobre as necessidades da própria formação, pois, não podemos ignorar, em um processo de formação profissional, as experiências e necessidades sociais apresentadas por quem deseja, adequadamente, preparar-se para o exercício de um determinado ofício.

Nessa linha de pensamento, cabe ressaltar que a universidade é o lugar próprio para a preparação formal do professor universitário, onde esse profissional deve buscar sua formação especifica para o magistério superior, focada no seu campo de conhecimento. Uma realidade que ainda parece ser muito incipiente no contexto do Brasil e da própria América Latina, o que torna as iniciativas de formação pedagógica insuficientes para que os profissionais, das diversas áreas do conhecimento, que atuam no Ensino Superior, tenham mais segurança para desenvolver o trabalho docente.

\section{REFERÊNCIAS}

ABRAHAM, Adda et al. (Org). El enseñante es también una persona. Barcelona: Gedisa, 1986.

BENEDITO, Vicente; FERRER, V. La formación universitária a debate. Barcelona: Universidad de Barcelona, 1995.

BRASIL. Lei n. 9.394/96, de 20 de dezembro de 1996. Estabelece as diretrizes e bases da educação nacional. Diário Oficial [da] República Federativa do Brasil, Poder Executivo, Brasília, DF, 23 dez. 1996. Disponível em:<http://www.planalto.gov.br/ccivil/ LEIS/L9394. htm>. Acesso em: 28 jul. 2010.

CHARLOT, Bernard. Os jovens e o saber: perspectivas mundiais. Tradução de Fátima Murad. Porto Alegre: Artmed, 2001. 


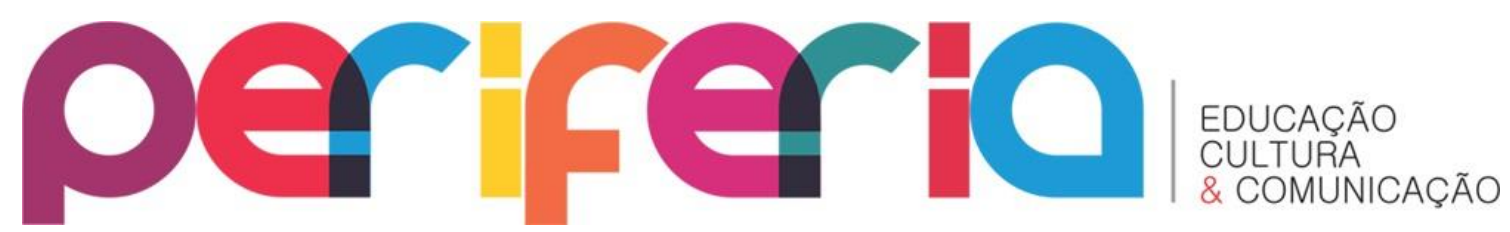

. Relação com o saber, formação dos professores e globalização; Tradução de Sandra Loguercio. Porto Alegre: Artmed, 2005.

CUNHA, Maria Isabel da. O bom professor e sua prática. 18. ed. São Paulo: Papirus, 2006.

A docência como ação complexa. In: (Org.). Trajetórias e lugares de formação da docência universitária: da perspectiva individual ao espaço institucional. Araraquara, SP: Junqueira \& Marin, 2010.

Formação docente e inovação: epistemologias e pedagogias em questão. In: Encontro nacional de didática e prática de ensino; 14., 2008, Porto Alegre. Trajetórias e processos de ensinar e aprender: lugares, memórias e culturas. Anais. Porto Alegre: Endipe, 2008.

DONATO, Maria Ermelinda. La formación docente de profesionales universitários: estrategias implementadas en la especialidad en docencia universitária, Facultad de Ciencias Veterinarias - UBA. In: Encontro nacional de didática e prática de ensino, $14 .$, 2008, Porto Alegre. Trajetórias e processos de ensinar e aprender: lugares, memórias e culturas. Anais. Porto Alegre: Endipe, 2008.

DUCROS, Pierre. La enseñanza: una dinamica de sistemas. In: ABRAHAM, Adda et al. (Org.). El enseñante es también una persona. Barcelona: Gedisa, 1986.

FERENC, Alvanize Valente Fernandes; SARAIVA, Ana Cláudia Lopes Chequer. Os professores universitários, sua formação pedagógica e suas necessidades formativas. In: Encontro nacional de didática e prática de ensino, 15., 2010, Belo Horizonte, MG. Convergências e tensões no campo da formação e do trabalho docente: políticas e práticas educacionais. Belo Horizonte: Autêntica, 2010. p. 573-589. (Coleção Didática e prática de Ensino).

FONTES, Carlos. Etapas da vida de professor. PROFBLOG: a educação em Portugal, 7 out. 2009. Disponível em: <http://www.profblog.org/2009/10/etapas-da-vida-deprofessor-i.html>. Acesso em: 16 nov. 2010.

GIL, Antônio Carlos. Didática do ensino superior. São Paulo: Atlas, 2006.

GOODSON, Ivor F. Dar voz ao professor: as histórias de vida dos professores e seu desenvolvimento profissional. In: NÓVOA, António (Org.). Vidas de professores. Porto: Porto Ed., 2007.

MIZUKAMI, Maria das Graças Nicoletti. Formação continuada e complexidade da docência: o lugar da universidade. In: Encontro nacional de didática e prática de 


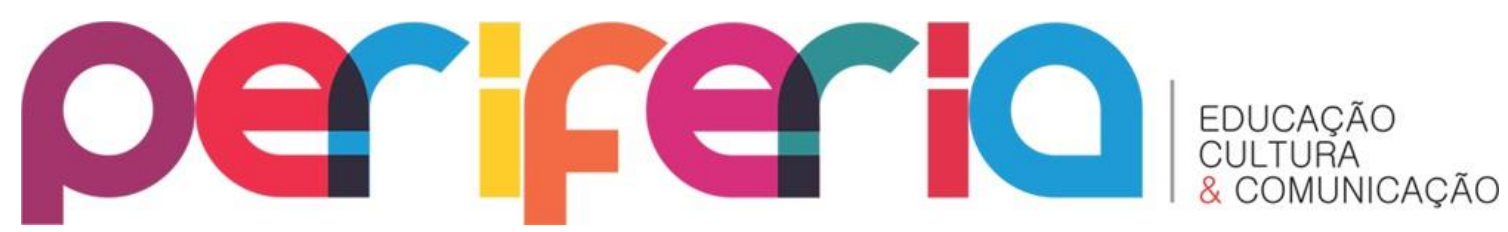

ensino, 14., 2008, Porto Alegre. Trajetórias e processos de ensinar e aprender: lugares, memórias e culturas. Anais. Porto Alegre: Endipe, 2008.

PIMENTA; ANASTASIOU, Lea das Graças. Docência no ensino superior. 2. ed. São Paulo: Cortez, 2005.

PLACCO, Vera Maria Nigro de Souza. Perspectivas e dimensões da formação e do trabalho do professor. In: Encontro nacional de didática e prática de ensino, 13., 2006, Recife. Anais. Recife: Endipe, 2006.

RAMOS, Elbo Lacerda; SIMONINI, Gizelda Costa da Silva. Docência: valorização profissional e identidade coletiva. In: NOVAIS, Santana Gercina; CICILLINE, Graça Aparecida (Org.). Formação docente e práticas pedagógicas: olhares que se entrelaçam. Araraquara, SP: Junqueira \& Marin, 2010.

ROCHA, Áurea Maria Costa. A formação de professores e a construção dos saberes da docência no curso de pedagogia da UFPE. 2008. Dissertação (Mestrado em Educação) ? Centro de Educação, Universidade Federal de Pernambuco, Recife, 2008.

TARDIF, Maurice. Princípios para guiar a aplicação dos programas de formação inicial para o ensino. In: Encontro nacional de didática e prática de ensino, 14., 2008, Porto Alegre. Trajetórias e processos de ensinar e aprender: lugares, memórias e culturas. Anais. Porto Alegre: Endipe, 2008.

Saberes docentes e formação profissional. 5. ed. Petrópolis, RJ: Vozes, 2005.

Saberes profissionais dos professores e conhecimentos universitários: elementos para uma epistemologia da prática profissional dos professores e suas consequências em relação à formação para o magistério. São Paulo: Revista Brasileira de Educação, n. 13, jan./abr. 2000.

VIDAL, Diana Gonçalves. A docência como uma experiência coletiva: questões para debate. In: Encontro nacional de didática e prática de ensino, 15., 2010, Belo Horizonte, MG. Convergências e tensões no campo da formação e do trabalho docente: políticas e práticas educacionais. Anais. Belo Horizonte: Endipe, 2010. 